\title{
As Cetariae na Província da Hispânia Bética: O GARUM ENQUANTo CONTINUAÇÃo de uMa Prática ECo- NÔMica E CULTURAL Fenício-PÚNico EM GADES E SUA RESSIGNIFICAÇÃO EM CONTEXTO ROMANO
}

Rodrigo Araújo de Lima ${ }^{1}$

\begin{abstract}
RESUMO: Produzidos nas cetariae da Hispânia Bética o garum e seus derivados foram iguarias alimentares introduzida na dieta latina tanto por suas qualidades gastronômicas e medicinais quanto pelo seu status. Neste artigo descreveremos a continuação da prática das salgações fenícias e púnicas estabelecidas na cidade fenícia de Gádir, mantida na Gades romana e absorvida pela dieta romana.
\end{abstract}

PALAVRAS-CHAVE: Produção fenício-púnica; Garum; Bética; Continuidade; Dieta romana.

ABSTRACT: Produced in Hispania Baetica cetariae, the garum and its derivatives were delicacies introduced in the Latin diet for your gastronomical and medicinal qualities, and by its status. In the article, we will describe the continuity of these Phoenician and Punic brine practice stablished in the Phoenician city of Gadir, maintained in the Roman Gades and absorved by the roman diet. KEYWORDS: Phoenician-Punic Production, Garum, Baetica, Continuity, Roman Diet.

Amphora corrupto nec uitiata garo

Ao se referir à uma cortesã chamada Thais, Marco Valério Marcial (6, 93, 6) utiliza a composição epigramática acima, aplicando-a de modo a dizer que "nem uma ânfora apodrecendo de garum, cheira tão mal como ela" (Lejavitzer, 2000, p. 119). Não há dúvida de que garum foi um importante condimento a base de peixe amplamente apreciado na Antiguidade tanto por fenícios, púnicos, gregos e em especial pelos romanos (fig. 1). No entanto, qual seria a polêmica em relação a esse molho de peixe consumido pelas mais diversas camadas sociais de

\footnotetext{
${ }^{1}$ Mestrando em Arqueologia pelo Programa de Pós-graduação em Arqueologia do Museu de Arqueologia e Etnologia da Universidade de São Paulo (MAE/USP) sob a orientação da Prof ${ }^{\mathrm{a}}$. Dr ${ }^{\mathrm{a}}$. Maria Cristina Nicolau Kormikiari Passos (MAE/USP). Membro do Laboratório de Estudos sobre a Cidade Antiga (LABECA) e membro do grupo de estudos do CNPQ Arqueologia Interativa e Simulações Eletrônicas (Arise) Bolsista Capes. E-mail: rodrigo.araujo.lima@usp.br. Agradeço os membros do LEIR-MA e a Revista Mare Nostrum pelo convite e pelo diálogo estabelecido durante nossa apresentação no Congresso de Pesquisadores e Pós-graduandos do LEIR-MA em 2016.
} 
Roma tanto nas províncias quanto na capital? Mesmo ironicamente desmerecido por alguns autores antigos, como veremos adiante, o garum conquistou a mesa romana se tornando uma verdadeira mania como afirmou Maguelone ToussaintSamat, (2009, p. 338) sendo amplamente utilizado na culinária, como pode ser atestado nas receitas gastronômicas que chegaram até nossos dias (cf. Apício, De Re Coquinaria). Usado tanto como um tempero como um unguento medicinal o garum, o liquamen, o hallec e a muria estão entre os condimentos mais apreciados pela antiga cozinha romana sendo também os mais comentados pelas fontes clássicas (Areteu, 1, 2).

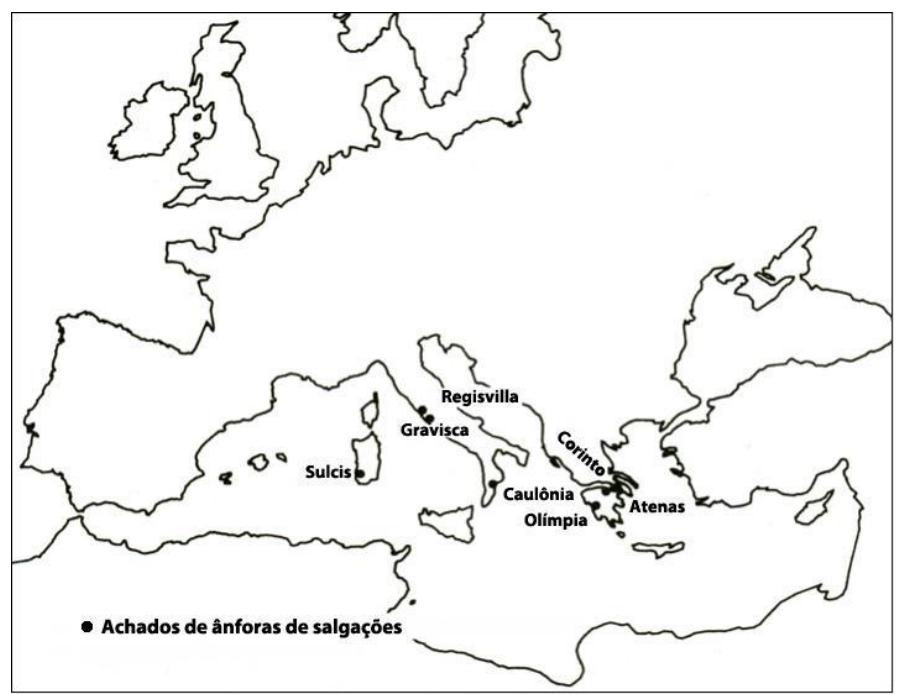

Fig. 1: Distribuição das ânforas contendo os molhos produzidos nas salgações fenícias durante o século VI-V a.C. (López Castro, 1995: p. 65; Adaptado por Araújo De Lima, 2017).

No que diz respeito a sua origem autores como Ponsich, Tarradell e posteriormente Étienne ${ }^{2}$, preferem afirmar que possivelmente o garum, a muria e o hallec seriam condimentos de origem púnica (Botte, 2009, p. 13; Martin, 1981, p. 53). No entanto, não há um consenso entre os pesquisadores sobre o povo criador desse molho. Arqueologicamente, como veremos adiante, as oficinas de salgação se concentram mormente na Península Ibérica, especificamente na região da

\footnotetext{
${ }^{2}$ Após publicar um artigo afirmando que o garum sociorum era de origem grega, Robert Étienne (1970). Segundo Martin (1981, p. 53), em 1971, Robert Etienne, durante o I Simpósio da Economia Antiga da Península Ibérica, afirmou que as indústrias antigas de conserva, como o garum eram invenção grega e que os púnicos a haviam copiado. No entanto em 2006 em suas retratações Étienne revê sua postura e assume o posicionamento de seus colegas considerando uma origem púnica que o garum (apud Botte, 2009, p. 13).
} 
atual comunidade autônoma de Andaluzia. Até o momento há evidências arqueológicas de uma intensa produção de garum nessa área ainda no século VI a.C. Sob Roma, as oficinas de salgação aumentam suas dimensões e se expandem para outras regiões ibéricas, fato que nos leva a considerar a Ibéria enquanto local primaz, dentre as demais áreas mediterrânicas, em vistas de suas excelentes condições climáticas, biológicas e ecológicas para a feitura da conserva. Vale lembrar que os assentamentos fenícios já dispunham de uma longa tradição de oficineiros acostumados à realização dessa atividade.

Segundo Robert Curtis (1983, p. 232) há algumas décadas os pesquisadores acreditavam que nossos estômagos não suportariam um prato preparado com garum. Essa ideia, atualmente, encontra cada vez menos seguidores, tanto que autores como Pierre Grimal, Thomas Monod afirmam que é difícil acreditar que o garum fosse realmente a podridão e a perversão do gosto uma vez que as cetariae, as oficinas de salgação de peixe, floresceram desde o século VI a.C. e seus produtos, o garum e seus derivados foram consumidos continuamente por um milênio (1952, p. 27).

O primeiro (e principal) argumento utilizado para infamar esse molho de peixe diz respeito ao seu mal cheiro. $\mathrm{O}$ seu longo processo de produção, como veremos adiante, provavelmente causou repulsa aos escritores antigos. No entanto tal como conclui Grimal e Monod (1952), Claude Jardin (1961) também considera que o garum não cheiraria pior que o nuoc-mam ${ }^{3}$ asiático (apud Curtis, 1983, p. 232).

Dada a necessidade de acondicionamento de alguns gêneros alimentícios, Gabriela Martin (1981, p. 49) esclarece que as populações mediterrânicas foram obrigadas a desenvolver meios para a conservação de seus alimentos. No caso dos pescados, o sal marinho foi um recurso vital para a conserva.

Na Antiguidade havia duas formas de obtenção desse recurso. O sal marinho, a cristalização do cloreto de iodo $(\mathrm{NaCl})$, poderia ser obtido tanto pela evaporação da água do mar nos campos salineiros como poderia ser extraído de jazidas subterrâneas sendo o conhecido sal-gema, composto pelos cloretos de iodo, potássio $(\mathrm{KCl})$ e magnésio $(\mathrm{MgCl} 2)$. Tanto o sal marinho quando o sal-gema eram essencialmente constituídos pelo cloreto de sódio.

3 Molho de peixe vietnamita. 
Utilizado em grandes quantidades durante a salga dos peixes, o sal era um composto ideal para a prevenção da putrefação assim como neutralizava o cheiro fétido sendo um dos recursos mais explorados na Antiguidade para a manutenção de víveres. O peixe conservado no sal se tornava um produto seguro para o consumo humano uma vez que suportava seu armazenamento em ânforas assim como o transporte por longas distâncias, assegurando um abastecimento contínuo entre os povos mediterrânicos.

No que diz respeito ao seu processo de fabricação, temos os relatos de Plínio o Velho (História Natural, 13, 43) que resume o garum como sendo um alimento elaborado a partir das vísceras dos pescados de atum ou da cavala (Martin, 1981, p. 50). Para seu fabrico, os peixes eram macerados em sal e deixado em salmoura sob o sol durante dois ou três meses, produzindo um líquido de aspecto apodrecido.

Como o descrito por Curtis (1983, p. 233) o líquido límpido que se forma na parte superior do tanque é drenado e o produto sedimentado dá origem ao hallec, um derivado do garum, mais espesso, contudo mais barato, sendo popularmente mais acessível. Ainda segundo o autor, a fermentação era induzida por bactérias, provocando a maturação do preparo em um processo similar ao fabrico de diversas variedades de queijos.

Com o preparo reduzido a um molho viscoso, o líquido era coado, armazenado em ânforas e distribuído pelo Mediterrâneo, alcançando, ainda nos séculos VI-V a.C., a Península Balcânica, a Península Itálica e a Sardenha (López Castro, 1995, p. 65), como ilustrado na figura 1.

A muria por sua vez, seria um condimento que se distinguiria tanto do garum quanto do liquamen e do hallec, no entanto é muito difícil estabelecer qual teria sido a sua natureza. Para Botte $(2009,21)$, as fontes literárias nos dão recursos suficientes para melhor compreendermos o que de fato teria sido a muria. Seu significado original designaria uma salmoura (i.e. mistura do sal com a água) (Grainger, 2014, p. 7) utilizada para a preservação dos mais diversos gêneros alimentícios. Plínio o Velho $(H N, 31,40)$, se refere à muria enquanto um subproduto do sal:

[...] Em uma parte da Espanha, eles preparam uma salmoura para esse propósito, a partir de poços profundos, para os quais eles dão o nome de muria, sendo da 
mesma opinião deles, a madeira utilizada no processo faz uma considerável diferença, sendo o quercus (carvalho) a de melhor qualidade uma vez que as suas cinzas, não misturadas, tem a pungência do sal [...] (Plínio o Velho, $H N, 31,40$, Tradução nossa).

Para José Rodríguez Remesal (1998, p. 255), em seu estudo do papel da Hispânia na política alimentar do Império, durante o período de pesca do atum, (entre maio e julho) as oficinas de salgação, as cetariae - que se constituíam enquanto "um rosário de fábricas" -, se enchiam de vida para o fabrico dos condimentos da província de Alicante até a desembocadura do Tejo.

Segundo a RAMPPA (Rede de Excelência Atlântico-Mediterrânea do Patrimônio de Pesca da Antiguidade), só nas orlas do Ocidente Mediterrâneo e no Atlântico Norte até o momento há vestígios arqueológicos de 284 cetariae (fig. 2), sendo a Bética (40,50\%), a Lusitânia (26\%) e a Tarraconense (9,50\%) os maiores expoentes dessa prática econômica na Península Ibérica, representando juntas 76\% de todas as oficinas de salgação do Ocidente escavadas até o momento.

O período do desenvolvimento das salgações na Península Ibérica data de um momento anterior à conquista latina, sendo resultado de um novo arranjo econômico desenvolvido pelas fundações fenícias estabelecidas no litoral. A baila do fim do tráfico de metais, estabelecido pelos fenícios desde o século IX a.C. até o VI a.C., com a hinterlândia tartésica, as oficinas de salgação, que já existiam em quantias modestas, se transformam em uma das principais forças econômicas das cidades fenícias da Ibéria (Neville, 2007, p. 163-170). O início do século VI a.C. marca um período de grandes transições que atinge todo o território ibérico, reestruturando consideravelmente o padrão de organização dos assentamentos semíticos e alterando sua convivência com os povos autóctones.

Na baía de Cádiz os oficineiros fenícios gozavam de condições tanto ecológicas quanto climáticas adequadas para a manutenção das salgações. A migração de peixes do gênero scombridae, 4 tipo de peixe que se acredita ter sido muito

\footnotetext{
4 Assim como outros membros da família scombridae (cavala e serras) o atum migra das águas frias do Atlântico para o Mediterrâneo em meio e em junho, passando pelo Estreito. Após a desova, os cardumes retornam para o Atlântico nos meses de junho e julho (Neville, 2007, p. 169).
} 
utilizado na produção do garum, em conjunto com as salinas gaditanas, utilizadas até a atualidade, encontrou, sob o clima quente do sul da Ibéria, condições ideais para a organização das salgações.

A partir do século VI a.C., com o desenvolvimento de inúmeras salgações de peixe, as cidades fenícias obtiveram ganhos exponenciais a partir da atividade de salgacão da indústria conserveira e oleira, que atuava em conjunto. Tão grande foi a fama da Península Ibérica na produção do garum que as moedas cunhadas por algumas das cidades fenícias (e.g. como aconteceu com a produção monetária de Gádir a partir do século III a.C.), possuíam a representação do atum em seu reverso, utilizando-o como símbolo de sua riqueza, e no anverso o cunho representava Héracles/Melqart, divindade que teria um templo nas cercanias de Gádir, na ilhota de Sancti Petri, próximo à Cádiz e à cidade de Chiclana de la Frontera. Como podemos perceber na figura abaixo (fig. 3) nota-se o atum no reverso das moedas batidas por Gádir (atual Cádiz) e em Sexi (atual Almuñécar), cidade onde se descobriu um grande complexo de salgações (fig. 4).

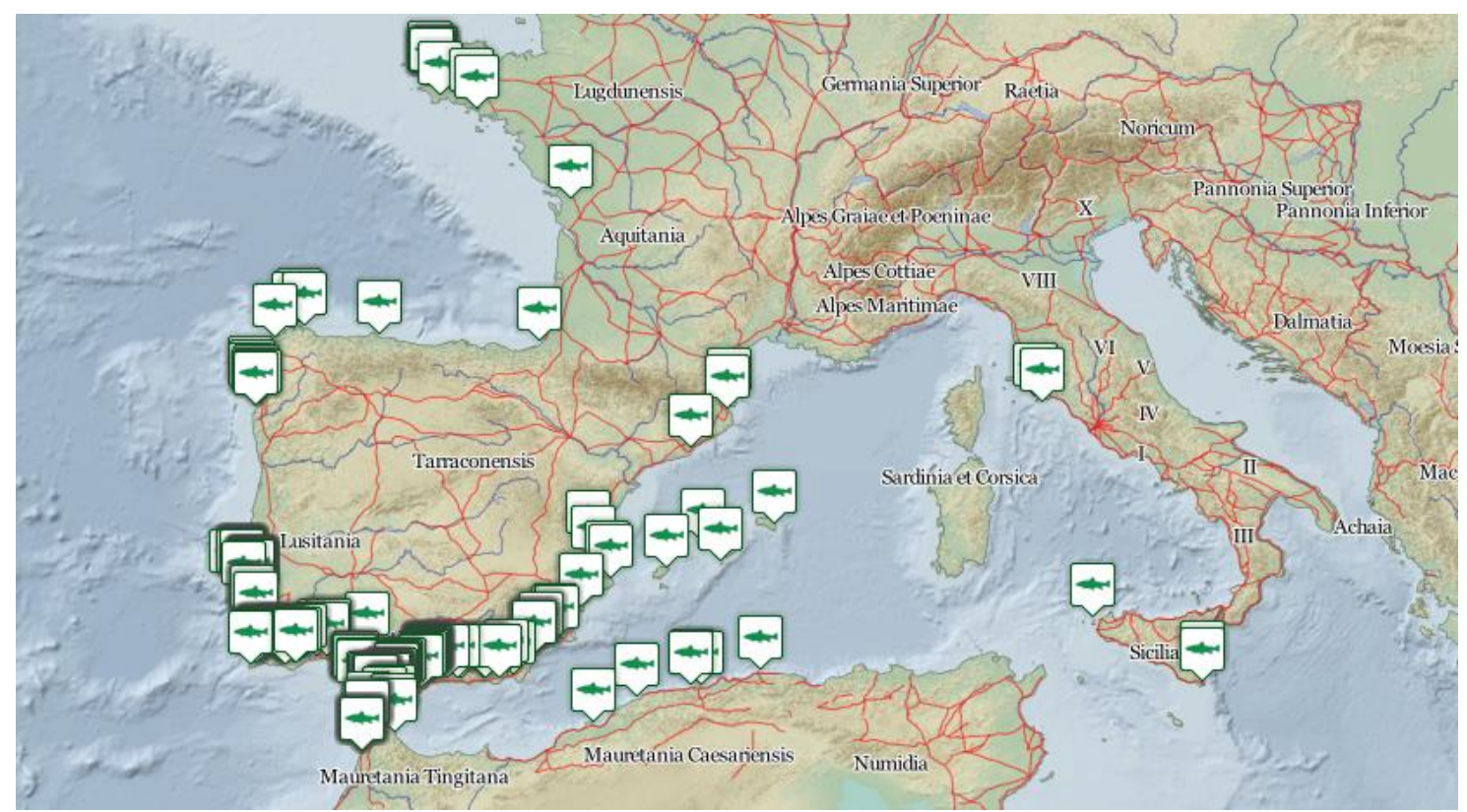

Fig. 2: Distribuição das cetareas pelo Ocidente Mediterrânico e Atlântico Norte5

5 Disponível em: <http://ramppa.ddns.net/pelagios>. Acesso em: o6 mar. 2018. 


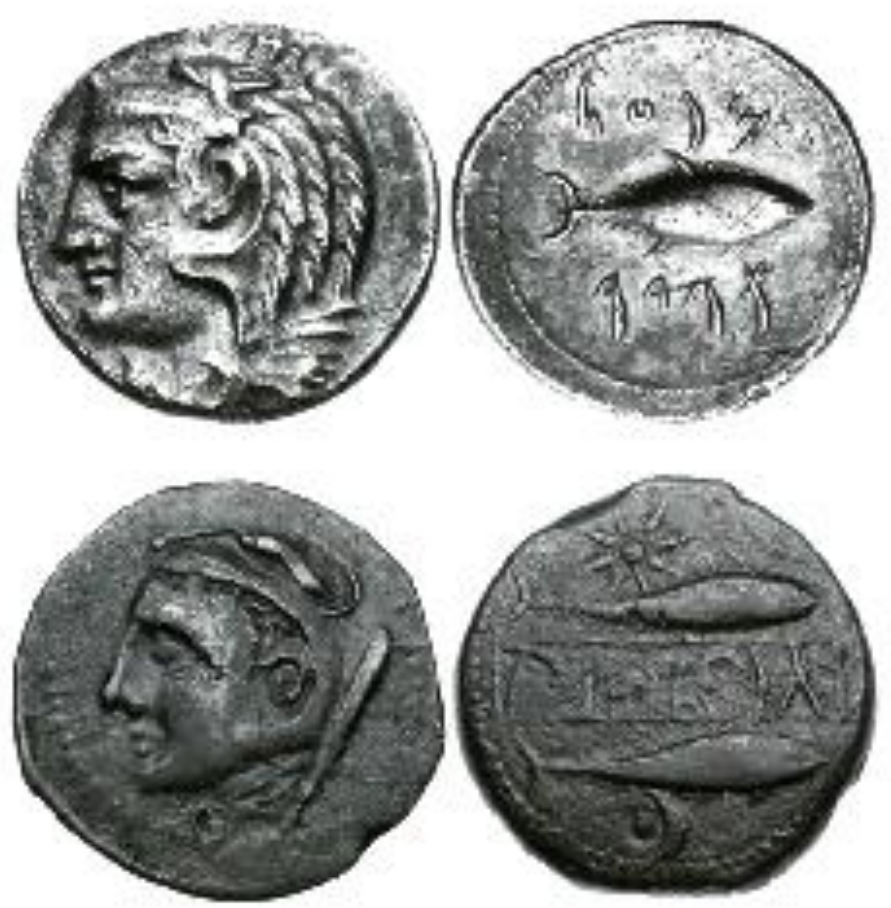

Fig. 3: Moeda de Gádir (século III a.C.) e de Sexi (Século II a.C.), no anverso se observa a representação de Melqart/Héracles e no reverso o atum com a legenda das duas cidades (Botte, 2009, p. 28; Adaptado por: Araújo De Lima, R. 2015).

A cidade de Gádir, segundo a teoria do Círculo do Estreito ${ }^{6}$ proposta por Miguel Tarradell (1967), era o centro nevrálgico de uma vasta rede de cidades fenícias que se localizavam entre o sul da Península Ibérica e o Norte Ocidental da África.

Tal como narra Estrabão (Geografia, 1,3,2; 3,2), os fenícios detinham as melhores terras da Ibéria desde tempos homéricos. As cidades semíticas, dispunham dos abundantes recursos madeireiros, agrícolas, minerais e piscícolas. Como dito anteriormente, as salinas que circulam a atual cidade de Cádiz podem ter sido na Antiguidade uma rica fonte para o abastecimento das salgações na ilha. Tal como afirma Neville, a empresa das oficinas de salgação pode ter sido

\footnotetext{
${ }^{6}$ A proposta de Tarradell sobre a existência de uma liga de cidades fenícias que abrangia as duas orlas (Península Ibérica e Norte da África Ocidental) deu condições para a valorização do Estreito de Gibraltar tanto enquanto uma ponte como uma fronteira. Arqueologicamente, os achados de cerâmicas do tipo Kuass em conjunto com a circulação de moedas cunhadas por Gádir formam o arcabouço da teoria do Círculo do Estreito. Essa área teria sido conduzida por uma talassocracia de Gádir (a romana Gades e a atual Cádiz). Gozalbes Cravioto (2015, p. 201) afirma que a preponderância de Gádir foi sobrevalorizada pelos investigadores espanhóis e contesta a aplicação do Círculo do Estreito para contexto romano imperial. Para esse autor, Roma não teria interesse em potencializar essa liga, mas justamente o contrário, uma vez que as duas orlas, enquanto províncias romanas, mostravam ritmos econômicos diferenciados (cf. 2015, p. 202).
} 
uma saída encontrada pelas fundações semíticas em controlar o seu território imediato. Uma vez que se supõe que o contato com os povos ibéricos na hinterlândia se tornou menos cordial, a partir do século VI a.C., possivelmente devido a redução das trocas resultantes da exploração das minas ibéricas. Os territórios se encontrariam em disputa com os recém organizados oppida ibéricos que passaram a controlar extensos territórios (Neville, 2007, 168-169).

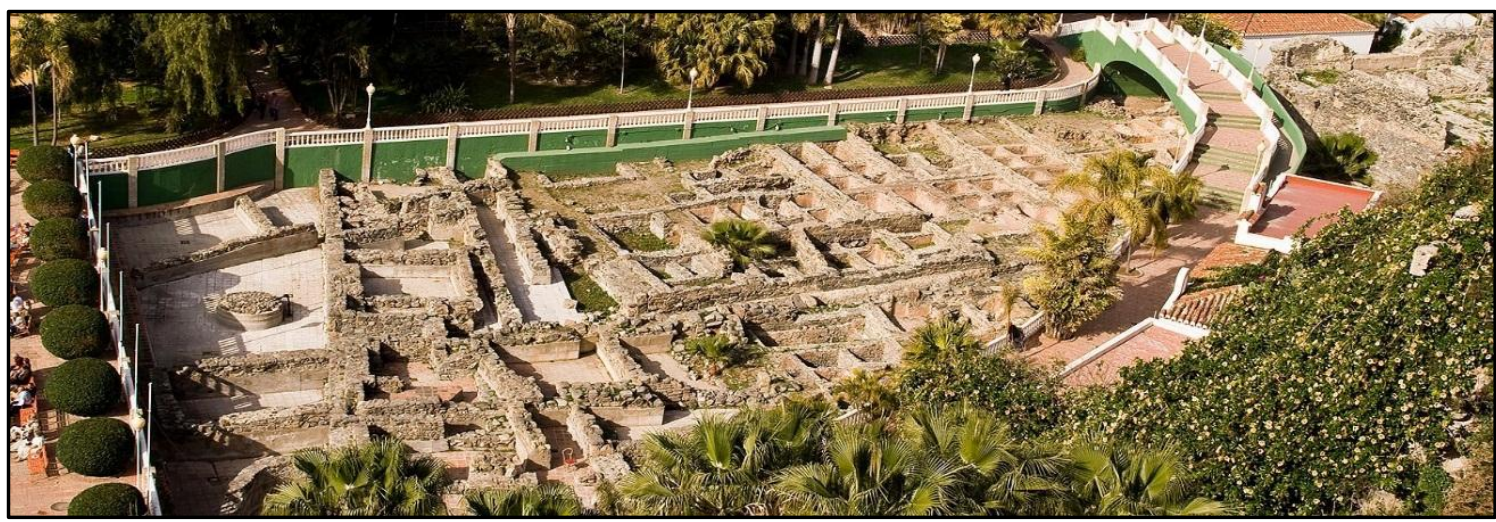

Fig. 4 - Fábrica de Salgação de Sexi no Parque el Majuelo (Almunécar) nos anos 70 a partir de escavações levadas a cabo por Manuel Sotomayor, Enrique Pareja e posteriormente Federico Molina Fajardo, a famosa salgação citada por Estrabão $(3,4,2)$ da cidade fenícia de Sexi - 'Ełı

Hannibal ad portas

A presença de Cartago já se fazia sentir desde o século VII a.C. até ser de fato concretizada pela conquista militar, conforme Pillar Uriel (1998, p. 52), através do esforço do general Amílcar Barca para conseguir o apoio do Senado de Cartago, os cartagineses marcham para a Península Ibérica, território que assentava fundações fenícias bem consolidadas, e iniciam campanhas para a conquista das tribos no interior das terras. Sob a égide da família Barca, Cartago passa a agir diretamente como herdeira das cidades fenícias do Levante assumindo a gestão das antigas fundações estabelecidas na Ibéria ainda nos séculos IX-VIII a.C. e explorando os abundantes recursos das salgações, das minas e da extração da tintura púrpura obtida do murex trunculus (Kormikiari, 1994, p. 8).

7 Disponível em: <http://www.turgranada.es/fichas/fabrica-romana-de-salazones-16891>. Acesso em: 21 nov. 2017. 
Temos que notar também sobre o importante processo de migração de cartagineses na Baía de Cádiz, fenômeno que se inicia na $2^{\circ}$ Guerra Púnica e perdura até 146 a.C. com a destruição de Cartago. De acordo com Antonio Sáez Romero e Dario Bernal-Casasola (2007, 346), pelos vínculos econômicos e culturais que os gadiritas mantinham com os cartagineses desde a época dos Barcas, novos contingentes populacionais se estabeleceram em Gádir. Segundo esses mesmos autores as últimas “ondas migratórias” podem ser atestadas a partir da introdução de novas práticas funerárias na necrópole gadirita onde se identificam askoi aviformes depositados nos enterramentos. No século II a.C. os resultados desses contatos também podem ser identificados pelo registro material cerâmico onde objetos cultuais de difícil interpretação são encontrados tanto na necrópole quanto nas oficinas locais (Sáez Romero; Bernal-Casasola, 2007, 346).

No que diz respeito aos envases, após a derrota de Aníbal em Zama (202 a.C.), a organização das salgações e das olarias não se alterou substancialmente. As oficinas ativas continuaram em maior parte ativas mesmo durante os anos de conflito. Já no século II a.C., houve o início de uma transformação no sistema de funcionamento das salgações. No que diz respeitos às técnicas de fabrico, o sistema tradicionalmente fenício-púnico, recebe novos tipos anfôricos (T-7.4.3.2/3, conhecido como Mañá c2b de inspiração centro-mediterrânica (Sáez Romero, Bernal-Casasola 2007, p. 345).

Não só Gádir como todas as cidades fenícias do Estreito testemunham a introdução de novos tipos cerâmicos, sendo o T-7.4.3.2 um tipo cerâmico exclusivamente gadirita de inspiração fundamentalmente cartaginesa. Se acredita que dada a grande diversidade de artesãos, esse recipiente inspiraria a variante $\mathrm{T}$ 7.4.3.3, coexistindo com o anterior até 100/90 a.C, até se tornar um século mais tarde, o modelo dominante. Ao que se sabe esses contentores possuíam funções múltiplas, sendo possível, portanto, pensarmos na sua difusão não só para o armazenamento do garum e seus derivados como para outros gêneros alimentícios (Sáez Romero et al., 2005, p. 874).

Uriel (1998, p. 53) afirma que a submissão aos romanos aconteceu em Cástulo (Linares), Baecula (Bailén), Ilipa (Lora del Río) e Carmo (Carmona) junto a todo o restante da Bética e da Turdetânia. Gádir preferiu estabelecer com Roma um pacto vantajoso, em que apenas três cidades ibéricas mantinham um tratado de aliança, sendo elas, Ampúrias, Sagunto e a própria Gádir. 
Será a partir da instalação do foedus em 78 a.C. que a sociedade gadirita começará a mudar substancial sua mentalidade e suas práticas político-econômicas. A epigrafia anfórica em latim, encontrada em vestígios cerâmicos em uma antiga oficina oleira escavada na rua Doctor Marañón na atual Cádiz, auxiliam na confirmação dessa mudança de paradigma. O uso das normas jurídico-administrativas romanas assim como a proliferação dos fundi oleiros e difusão de assentamentos rurais no litoral e no interior (no atual munícipio de Jerez de la Frontera e em El Puerto de Santa María) são marcadores de uma inserção cada vez mais profunda das antigas fundações fenícias ibéricas ao mundo romano (Sáez Romero et al., 2005, p. 345).

\section{Civitas Foederata}

Com a derrota de Cartago na Segunda Guerra Púnica, Gádir, como assinala Uriel (1998, p. 53), se alia à República Romana em 206 a.C. O nome fenício passa a ser transcritos como Gades versão latinizada do original. A cidade adquire o status de civitas foederata, posição que a manteve autônoma em relação à Roma. Desprovidos de Gádir, seu último bastião na Ibéria, os cartagineses foram expulsos da Península e se retiraram para o Norte da África (Havell, 2003, p. 267).

Em Gades, os Balbo, uma poderosa família que se acredita ser de origem fenícia ou púnica - assim como diversas elites provinciais -, se associaram à Roma e realizaram grandes reformas na cidade. Gades era então uma cidade pequena, mas de considerável importância uma vez que se conectava à via Augusta, a mais longa estrada romana na Península, e era local onde o governador celebrava suas audiências. Em 49 a.C., Gades receberá a visita de Júlio César que havia se tornado próximo da família Balbo (Ferreiro López, 2008, p. 311-309).

Segundo Ferreiro López (2008, p. 309), muito provavelmente por conselho do próprio Júlio César, em 61 a.C. Gades começa a adequar sua legislação aos "gostos de Roma”. Os tradicionais sufetes ${ }^{8}$ viriam a se converter gradualmente

$8 \mathrm{O}$ termo spt vocalizado como sufete se refere à um tipo de magistratura semítica presente nas cidades fenícias tanto levantinas quando em suas fundações. Como funcionava a justiça pouco conhecemos. Não há documentos que elenquem as penalidades previstas para crimes, tampouco como era executada a sentença e nem se os acusados tinham a possibilidade de se defenderem. Das fontes antigas gregas e latinas temos ecos sobre crucificações que dizem respeito sobretudo às categorias militares, como generais derrotados e mercenários em revolta, fato que pode dar condições de pensarmos em uma possível divisão da legislação das cidades entre regulamentos civis e militares (Dridi, 2006, p. 111). Esse tipo de juiz era eleito anualmente e se tornavam os 
em tribunos, assim como o senado semita se tornaria a típica cúria municipal romana (Ferreiro López, 2008, p. 317 apud Lomas, 1991, p. 104).

Durante a República e o Império a prática econômica da salgação do garum foi continuada e expandida, algo que pode ser atestado arqueologicamente pela presença de inúmeras fábricas dos períodos fenício, púnico e romano em Cádiz, tais como o sítio arqueológico musealizado de época romana Factoría de Salazones del Teatro Andalucía; as fábricas de salgação púnica de El Puerto de Santa Maria descritas no trabalho de Ruiz Gil (1988); assim como no complexo industrial de salgações gaditanas de Camposoto em San Fernando (Cádiz) estudado no artigo de Gago Vidal et al. (2000).

Martin (1981, p. 54) afirma que as fábricas no Estreito de Gibraltar formavam unidades de grande porte, sendo que as de Gades deveriam ser as maiores e mais numerosas, por que, juntamente com Cartago Nova, são as mais citadas nas fontes textuais.

\section{Conventus Gaditanus}

O Conventus Gaditanus (unidade administrativa que perdurou do século I a.C. até o $\mathrm{V}$ d.C.) era formado pela maior parte da província da Bética indo da desembocadura do Guadalquivir até Almería. A pesca continuava sendo uma atividade econômica característica tanto em Gades quanto nas demais cidades fenícias, a maior parte de seus habitantes vivia da pesca e da cetariae e das oficinas cerâmicas que a ela estava relacionada (Ferreiro López, 2008, p. 313).

\footnotetext{
responsáveis pelos caminhos que a cidade tomaria. Sufete: (Masculino; plural Sufetes). Magistrado cartaginês. Disponível em: <http://labeca.mae.usp.br/pt-br/glossary>. Acesso em: 20 de nov. 2017. Tito Lívio utiliza aqui o termo latim quaestor. Segundo Freund e Thiel em seu terceiro volume do Grand Dictionnaire de la Langue Latine (1862, p. 6). Quaestor é o nome de certas magistraturas romanas, dado a dirigentes das finanças do Estado. Em outros levantamentos, ainda segundo o mesmo autor, é o nome dado a indivíduos responsáveis pelos processos criminais individuais. Mas sempre como um mandatário do povo, como um comissário do processo criminal. Tito Lívio provavelmente tentou aproximar o cargo púnico ao cargo romano optando pelo termo latino para um entendimento aproximado desse tipo de magistratura semítica.
} 


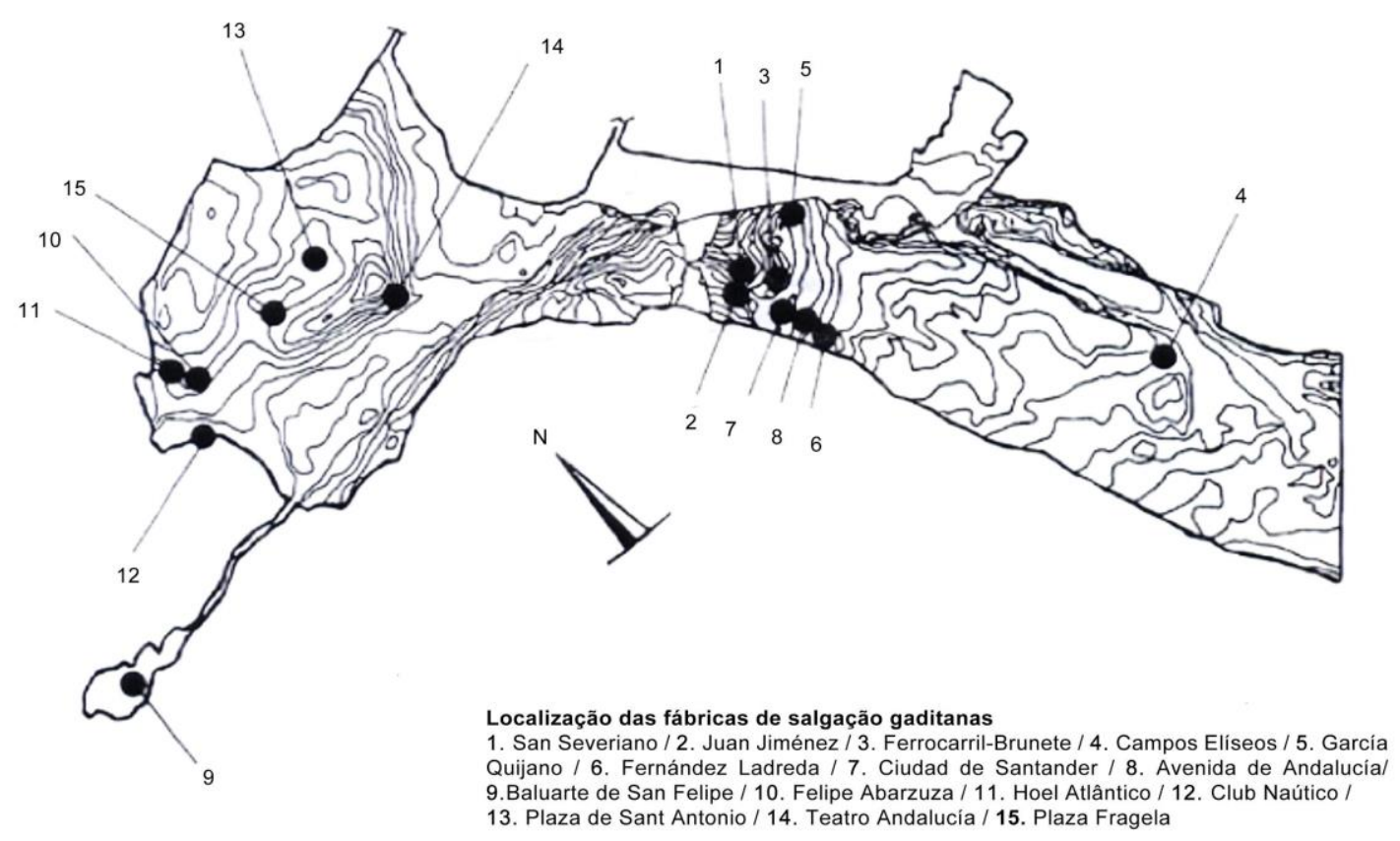

Fig. o5- Localização das fábricas de salgação em Gades. Disponível em: <http://www.blogsdecadiz.com>. Adaptado por: Araújo de Lima, 2017. Acesso em: 21 nov. 2017.

Seguramente, a Gades do século IV a.C. era uma cidade com características fenício-púnica. Estabelecida no arquipélago das ilhas Gadeiras (formado por Eritéia, Cotinussa e Antípolis), a cidade contaria ao menos com um porto ao seu dispor assim como possuiria diversas cetariae tanto suas duas ilhas principais, Eritéia (ilha em que se acredita ter sido erigido o centro urbano inicial fenício), Cotinussa (ambiente reservado para a necrópole semítica arcaica) (fig. 5), Antípolis (atual San Fernando, ilha que tradicionalmente abrigava oficinas de salgação) quanto nas praias de El Puerto de Santa María

A topografia é um dos elementos que distingue as fundações fenícias frente aos demais povos mediterrânicos. Era frequente que sua paisagem fosse formada por promontórios ou ilhas não muito distantes do continente beneficiada por águas rasas. Para a proteção do porto, no geral o assentamento era erigido no interior de baías ou grandes lagos, abrigado dos efeitos de marés mais violentas (Araújo de Lima, 2017, p. 324).

Essa situação iria mudar graças ao exitoso cursus honorum da família Balbo. Possuidores de remotas raízes fenícias ou púnicas, os Balbo eram uma fa- 
mília oligárquica gaditana, provavelmente enriquecida pelas atividades mercantis, que firmou uma vantajosa aliança política com Roma (Rodríguez Neila, 2009, p. 308).

Com a influência política conseguida tanto por Lúcio Cornélio Balbo, o Maior, quanto por seu sobrinho Lúcio Cornélio Balbo, o Menor, a pequena Gades foi engrandecida e reorganizada com o intuito de abrigar edifícios públicos próprios de uma cidade romana.

Durante sua expansão, o subúrbio de Didyme, foi construído para servir Gades (Estrabão, 3, 5, 3). Era imperativo também a construção de um novo porto, no continente - e se acredita que, o mesmo, conhecido como Portus Gaditanus se encontrava no atual município de El Puerto de Santa Maria -. A construção de outro porto não se justificaria pela antiga área portuária ter dimensões reduzidas, mas sim graças à facilidade do embarque dos produtos do continente, entre eles o garum e seus derivados (Ferreiro López, 2008, p. 319).

A indústria conserveira dependida, naturalmente, do comércio e produção do sal que se encontrava organizado em monopólios estatais durante o período cartaginês e romano. É provável que para o abastecimento das salgações, as instalações estivessem próximas a salinas. Martin (1981, p. 58) aponta que dificilmente uma fábrica seria construída sem ter uma mina de sal em suas proximidades para facilitar o fluxo da produção e comenta que, por mais que os sítios mineiros possam ter sido abandonados, os topônimos podem indicar a sua existência, como no caso de Alcácer do Sal (Salacia), Salinas, Las Salinas de San Rafael, El Salinar, El Saladar, Lagunas de Salinas, dentre outras localidades. Podemos concluir que os topônimos podem auxiliar, em alguns casos, até mesmo na reconstrução da paisagem pretérita.

\section{Liquoris exquisiti}

Martin afirma que o garum se difundiu mais entre os pobres, que "formavam a grande massa da população junto com os escravos" (1981, p. 59) justamente por ser mais barato que a carne de porco, aves e boi, consumidas pelos mais abastados. No entanto, seu consumo pode ser atestado no interior das domus romanas, como em Roma, Pompéia e em Herculano (Curtis, 1983, p. 236237). O garum teria atingido preços tão exorbitantes que, segundo a comparação 
de Toussaint-Samat (2009, p. 338), sequer o caviar moderno seria capaz de superá-lo. Durante a época de Júlio César, a autora afirma que 1 congius (aproximadamente três litros e um quarto) de garum custaria 500 sestércios, que nos valores modernos corresponderia em algo como £4.000,oo.

Havia categorias diferenciadas para as mais diversas qualidades do garum, algo que implicaria em seu valor de mercado. A flos gari (flor do garum) provavelmente fosse a primeira porção do líquido retirado após o final de seu processo de produção, sendo, portanto, de qualidade superior. Outras qualidades conhecidas seriam o optimum (melhor), o primum (primeiro) o excellens e o praecellens (excelentes). No que se refere aos de qualidade inferior, conhecemos os tipos secundum (segundo) e penuarium (baixa qualidade). Existiam também marcas especiais do garum tal como o garum castum, castimoniarum e o castimoniale, que seriam consumidos apenas por consumidores judeus, que segundo seus preceitos, não poderiam ingerir o peixe sem as escamas (Déry, 1998, 106).

Portanto, pensar tão somente na divisão social, entre ricos e pobres, castra o entendimento da individualidade que permeava o mundo romano (Lejavitzer, 2000, p. 119; Blázquez, 1998, p. 101).

Amalia Lejavitzer (2000, p. 119) levanta importantes pontos em seu trabalho para pensarmos o garum. É importante relembrar que os romanos, antes do Império, eram conhecidos por sua frugalidade e austeridade, situação que se inverteu em algumas camadas sociais com a passagem da República para o Império.

Essa mudança de comportamento foi assumida por Montesquieu (1734) como sendo resultado de um fluxo de tesouros que fluiu para dentro da cidade, vindos das conquistas dos generais. Fato este que, para o autor, acabou com a austeridade romana e produziu um gosto exagerado pelo luxo e pela ostentação. Montesquieu chega a afirmar que este afluxo de riquezas fez com que "antigas máximas e virtudes fossem se perdendo paulatinamente, sem possibilidade de retorno" (Montesquieu, [1734] 2005, p. 11).

No banquete de Trimalquião na obra Satíricon de Petrônio, o peixe, enquanto alimento, se encontra presente na narrativa, nadando em um rio de molho temperado (Petrônio, Satíricon, 36, 6). Ainda nessa sátira fica evidente a crítica de Petrônio sobre os hábitos do rico Trimalquião, que havia sido um ex-escravo. Em sua tentativa de demonstrar para seus convivas a grandeza de sua fortuna o 
anfitrião mostra como seus hábitos são na realidade grosseiros. Como moral, Petrônio nos faz entender que por mais próspero que Trimalquião possa ter conseguido se tornar, não superou costumes vulgares. Nesse festim fictício, o molho com os peixes ainda nadando, pode ser interpretado enquanto uma metáfora sobre $o$ status que o condimento das salgação propiciava àquele que o adquirisse. $O$ trecho clarifica como fator social desse tempero era útil na demonstração de riqueza e poder durante as refeições comunais.

Ora, sabe-se que o garum conquistou o paladar romano e, nessa perspectiva, podemos interpretá-lo no interior do movimento de crioulização tal como foi proposto por Jane Webster (2001). Webster, entende que as trocas entre Roma e suas províncias não aconteceriam em uma via única, mas sim em um movimento de mão-dupla que a autora denomina como crioulização. Esse conceito se mostra interessante para uma melhor compreensão da difusão do garum pelas mais diversas camadas. Por meio dele podemos supor que a incorporação de práticas alimentares exógena foi um outro elemento que também crioulizou a elite romana.

Assim como o figo fresco exposto por Catão o Velho diante do Senado Romano (Plutarco, 27, p. 1; Harris, 1998, p. 9; Dumas, 2006, p. 140), fora símbolo da potência, ameaça e proximidade que Cartago representava, o garum era considerado, para os autores latinos (Plínio o Velho, HN, 31, 43, 93; Senêca, Epístolas, 95, 25) como símbolo da podridão e da corrupção. Apesar das difamações e da inquestionável popularidade desse molho de peixe, acusado de exalar mal cheiro, a quantidade de sal utilizada era tamanha que não permitiria o processo de putrefação. O garum era na realidade fermentado não exalando mal odor durante seu fabrico uma vez que o sal inibia o odor (Déry, 1998, p. 108).

Déry (1998, p. 110) afirma que a figura do peixe teria um apelo estético em Roma uma vez que a representação desse animal pode ser encontrada em diversas cenas de mosaico em casas de elite. Há representações do peixe tanto em seu ambiente natural quanto em cenas de pesca, sendo um ingrediente constantemente ilustrado em murais e mosaicos de pescadores que buscavam promover suas mercadorias.

Como já citamos anteriormente, o garum estaria, em algumas ocasiões, ligado à uma prática social vinculada a comensalidade, de modo a exibir o poder 
de seu adquirente, sendo também um importante conservante para outros alimentos além de possuir extensas capacidades medicinais, tais como servir de analgésico, anestésico e também como soro reconstituinte (Lejavitzer, 2000, 127). Plínio ( $H N, 31,44)$ elenca as propriedades medicinais do garum para os mais diversos (e curiosos) casos:

[...] Queimaduras recentes também podem ser curadas pela agência do garum, com o devido cuidado de não mencionar o nome do produto durante a aplicação. É útil também para as mordidas de cachorro, e em particular de crocodilo, assim como é um tratamento para úlceras serpiginosas ou sórdida. Para ulceração e dor na boca e nas orelhas é um remédio maravilhosamente útil [...] (Plínio o Velho, $H N$, 31, 44, Tradução nossa).

Plínio conclui comentando sobre as propriedades curativas da muria:

[...] A muria também, enquanto um molho salgado que mencionamos (no final do Capítulo 42 do Livro 31) tem certas funções adstringentes e mordente dentre outras propriedades discutidas, sendo altamente funcional para a cura da disenteria, mesmo quando a ulceração já atacou os intestinos. Injeções também são feitas no ciático, e para os fluxos celíacos de natureza inveterada [...] (Plínio o Velho, $H N$, 31, 44, Tradução nossa).

Os relatos acima nos dão condições de pensarmos o garum e seus derivados para além do consumo voltado somente para a subsistência da vida, e da sua ostentação enquanto produto de luxo. A prática social intrínseca desse alimento também o indica como um medicamento eficaz para os mais diversos males.

O liquoris exquisiti referido por Plínio $(31,43,93)$ se tornou um verdadeiro paradoxo (Lejavitzer, 2000, p. 117), sendo tanto um necessário condimento quanto uma verdadeira tendência para o paladar latino de seu tempo.

\section{Considerações finais}

A leitura dos textos clássicos quando se refere ao garum deve ser analisada com cautela, como afirma Curtis (1983, p. 240). Embora não possamos negar o valor excepcional das fontes históricas não podemos deixar de reconhecer que o texto, por muitas vezes, apresenta um certo descompasso com a realidade 
não respondendo objetivamente por todos os acontecimentos do passado. Nesse sentido, as fontes materiais em diálogo com as fontes históricas apresentam um maior potencial interpretativo acerca do que foi o fenômeno do garum para além de seus aspectos gastronômicos.

De fato, o garum e seus derivados foram consumidos em larga quantidade na dieta diária romana, da República ao Império, nas mais diversas camadas sociais, assim como também fica evidente a amplitude das cetariae instaladas na Bética. Difundido anteriormente à conquista romana, o garum já era famoso em vários pontos do mediterrâneo desde o século VI a.C.

É perceptível que o potencial do garum não se restringia somente às práticas alimentares e comensais. Sendo também um útil tratamento medicinal para as mais variadas mazelas. Por mais exótico e degradante que o molho fosse considerado para alguns escritores latinos, podemos afirmar que não foi um produto de baixa circulação. Segundo o conselho de Toussaint-Samat (1991) é preciso tratar não somente da história natural, mas também da história moral (e medicinal) dos alimentos e sua significação nas diferentes sociedades mediterrânicas.

Artigo recebido em 30.12.2017, aprovado em 07.03.2018. 


\section{REFERÊNCIAS BIBLIOGRÁFICAS}

Fontes primárias

Aretaeus. De curatione acutorum morborum libri duo, translated by Francis Adams. Boston: Milford House, 1972.

Apicius. Cookery and dining in imperial Rome: a bibliography, critical review, and translation of the ancient book known as Apicius De Re Coquinaria, translated by Joseph Dommers Vehling. New York: Dover Publications, 1977.

Martial. Epigrammaton. Liber Vi. Translated By Wilhelm Heraeus; Jacobus Borovskji. Leipzig, 1925.

Petronius. Satyricon Liber. Translated by Michael Heseltine. London: William Heinemann, 1913.

Pliny, the Elder. The Natural History. translated by Bostock, J. M. D; Riley, H. T; Mayhoff, K. F. T. London: Tailor and Francis, 1855.

Plutarch. The life of Cato the Elder. Translated by Bernadotte Perrin. London: William Heinemann, 1914.

Strabo. Geography. Translated by Hamilton, H. C; Falconer, W. M. A. London: George Bell \& Sons, 1903 .

Titus Livy. The History of Rome. Book 28. Translated by Frank Gardener Moore. London: William Heinemann, 1949.

Bibliografia crítica

Araújo de Lima, Rodrigo. A casa fenício-púnica. Revista Heródoto, vol. 2, n. 1, 2017, p. 323-345.

Botte, Emmanuel. Salaisons et sauces de poissons em Italie du sud et em Sicilie durante l'Antiquité. Nápoles: Collection du centre Jean Bérard, 2009.

Bernal-Casasola, Dario; Sáez-Romero, Antonio. Saladeros y alfares en Gadir. La perspectiva fenicio-púnica del Extremo Occidente. In: López Castro, José Luis (ed.). Las ciudades fenicio-púnicas en el Mediterráneo Occidental. Almería: Editorial Universidad de Almería, 2007, p. 317-368.

Blázquez, José María. Los productos de la tierra. In: Almagro-Gorbea, Martín. Hispania, el legado de Roma: en el año de Trajano. Madrid: Ministerio de educación y cultura, 1998, p. 95-102.

Curtis, Robert. In Defense of Garum. The Classical Journal. vol. 78, n. 3, 1983, p. 232-240.

Déry, Carol. Fish as food and symbol in Ancient Rome. In: Harlan Walker (ed.) Fish from the Waters. Totnes. Prospect Books: 1998, p.94-115.

Dumas, Alexandre. Grande Dicionário de Culinária. Tradução André Telles. $1^{\circ}$ Edição. Rio de Janeiro: Zahar, 2006.

Dridi, Hédi. Carthage et le monde punique. Paris: Les Belles Lettres, 2006. 
Ferreiro López, Manuel. Cádiz en el tiempo de César y los Balbo. La ordenación territorial en la Bahía de Cádiz a finales de la República Romana. Revista Atlántica-Mediterránea de Prehistoria y Arqueologia Social, Cádiz, vol. 10, 2008, p. 309-324.

Freund, Willian; Madvig, Johan Nikolai; Thiel, Jean-François-Napoleón. Grand Dictionnaire de La Langue Latine. Tome Troisième. Paris: Firmin-Didot, 1862.

Gago Vidal, María et al. El complejo industrial de salazones gaditano de Camposoto, San Fernando (Cádiz): Estudio Preliminar. Habis. n. 31. 2000, p. 37-61.

Gozalbes Cravioto, Enrique. El círculo del Estrecho: en la Antigüedad: Una revisión historigráfica. Índice Histórico Español. n. 128, 2015: p.175-209.

Grainger, Sally. Garum, Liquamen and Muria: a new approach to the problem of definition. In: Botte, Emanuelle; Leich, Victoria. Fish and ships: production and commerce of salsamenta during antiquity, Rome 18-22 juin 2012 ed. Bibliothèque d'Archéologie Méditeranéenne et Africaine 17 (Centre Camille Julien, Aix-en Provence, 2014. p. 37-46.

Harris, Jessica. The African Cookbook: Tastes of a Continent. Nova Iorque: Simon \& Schuster, 1998, p. 9-10.

Havell, Herbert Lord. Ancient Rome: The Republic. Londres: Geddes and Grosset, 2003.

Lejavitzer, Amalia Garum paradoxum, misterio y maravilla de la cocina romana. Noua Tellus, vol. 18, n. 2, 2000, p. 115-128.

López Castro, José Luis. Hispania Poena: Los fenicios en la Hispania Romana. Barcelona: Crítica, 1995.

Montesquieu, Charles-Louis de Secodant. Considerações sobre as causas da grandeza dos romanos e da sua decadência: concentração do poder. Tradução: Pedro Vieira Mota, $2^{\circ}$ Edição, São Paulo: Editora Saraiva, 2005.

Martin, Gabriela. Garum e Salsamentum. Técnicas de salga de peixe na Antiguidade. Clio. Revista do Curso de Mestrado em História. n. 4, 1981, p. 49-6o.

Neville, Anne. Mountains of silver \& Rivers of god: The Phoenicians in Iberia. Oxford: Oxbow Books, 2007.

Rodríguez, Remesal. Hispania en la política alimentaria del imperio romano. In: Hispania. El legado de Roma. Zaragoza: Tipolinea, 1998, p. 338.

Rodríguez Neila, Juan Francisco. Los Cornelios Balbos. Políticas y mecenazgo entre Gades y Roma. In: Bernal, Darío; Arévalo, Alicia (orgs.) El theatrum balbi de Gades. Actas del Seminario "El Teatro Romano de Gades. Una mirada al futuro". Cádiz: Servicio de Publicaciones de la Universidad de Cádiz, 2011.

Ruiz Gil, José Antonio. Las Factorías de Salazones Púnicas de El Puerto de Santa María. Cádiz. Dissertação de Mestrado, Universidade Autônoma de Madrid, 1988.

Sáez-Romero, Antonio; Bernal-Casasola, Dario; Montero Fernández, Ana. La producción anfórica tardopúnica de Gadir (S. II-I a.C.): Nuevos datos aportados por el alfar de c/asteroides (San Fernando, Cádiz). In: Arruda, Ana Margarida (ed.). Fenícios e púnicos, por terra e mar. Vol. 2. Centro de Arqueologia da Universidade de Lisboa, 2005, p. 867-878. 
Uriel, Pillar Fernández. Fases de la conquista romana e inicios del asentamiento. In: Almagro-Gorbea, Martín. Hispania, el legado de Roma: en el año de Trajano Madrid: Ministerio de educación y cultura, 1998, p. 51-64.

Webster, Jane. Creolizing the Roman Provinces. American Journal of Archaeology, vol. 105, n. 2, 2001, p. 209-225. 